\title{
Der Lohn der Mühe
}

Der professionelle Umgang mit Konflikten verschafft Ihnen mehr Ressourcen für Ihre eigentlichen Aufgaben. Anstatt sich im täglichen Kleinkrieg aufzureiben gestalten Sie Lösungen. Sie schaffen sich und anderen wertvolle Freiräume. Je erfolgreicher Sie in Sachen Konfliktmanagement sind, desto positiver wirkt sich das auch auf Ihre gesamte Umgebung aus. Es wird nicht immer Friede, Freude, Eierkuchen herrschen, aber die Atmosphäre wird insgesamt spürbar konstruktiver, offener und produktiver. Und Sie werden die Erfahrung des amerikanischen Konfliktmanagement-,,Gurus“ William Ury bestätigt finden:

Es gibt keine Garantie. Nicht jede Differenz lässt sich überwinden. Aber bei sehr vielen, weitaus mehr, als allgemein angenommen, ist das möglich.
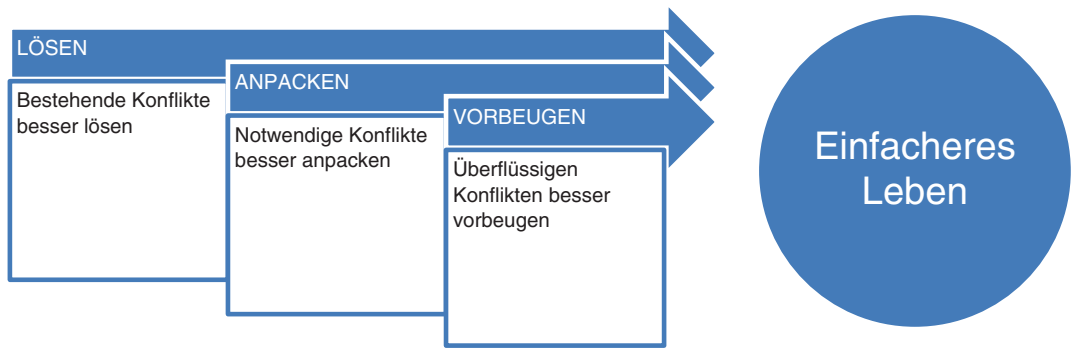